\section{Regression of carcinoid tumour with cyproheptadine}

Patients with the carcinoid syndrome are usually treated initially with serotonin antagonists. Although this may control diarrhoea and flushing, it does not usually control other features of the disease. ${ }^{1}$ We observed a patient with the carcinoid syndrome whose tumour regressed while he was receiving cyproheptadine. We then treated a patient with a non-functioning apudoma, which also regressed. We report here these two cases.

\section{Case reports}

Case 1-A 66-year-old white man presented in April 1980 with a two and a half year history of flushing and watery diarrhoea. At laparotomy in July there was a large secondary deposit in the right lobe of the liver and several smaller deposits in the right and left lobes. The primary was in the small bowel, which was matted together, and carcinoid tumour was confirmed on biopsy of mesenteric nodes. Over the next three months he lost weight and had continuous pain over the right lower ribs. In September the urine concentration of 5-hydroxyindole-acetic acid ranged from 43 to $59 \mathrm{mg} / \mathrm{g}$ creatinine. Computed tomography showed a large mass in the right lobe of the liver (figure (left)). He started treatment with cyproheptadine $4 \mathrm{mg}$ three times a day and over the next two and a half months the pain resolved. By April 1981 he had regained $16 \mathrm{~kg}$ and no 5-hydroxyindole-acetic acid was detectable in his urine. Repeat computed tomography showed considerable regression of the tumour (figure (right)).
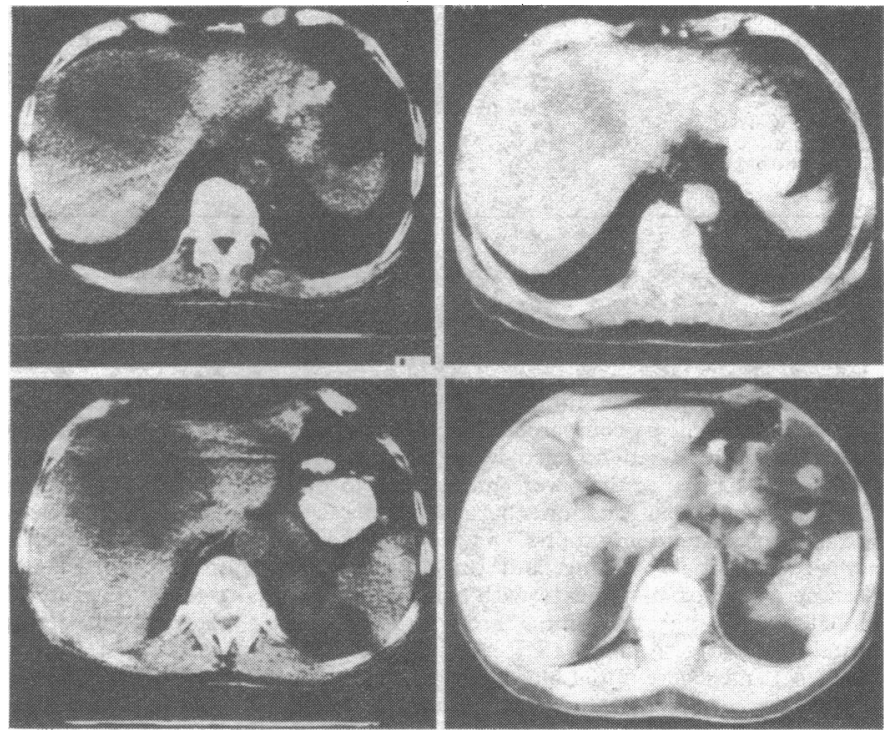

Computed tomograms of the liver in case 1 (left) before treatment with cyproheptadine, September 1980; (right) after treatment, April 1981.

Case 2-A 43-year-old white man underwent laparotomy in September 1977 for recurrent abdominal pain thought to be due to biliary tract disease. A pancreatic tumour was enucleated, and there were secondary deposits in the liver. Histology showed an argentaffin-negative malignant apudoma with slight argyrophilia. He was well until January 1981, when he developed right-sided upper abdominal pain and was found to have hepatomegaly. Disease progressed over four months until his liver was $13 \mathrm{~cm}$ below the right costal margin. Serial ultrasonography of the liver in March and May showed progression of metastases. In May his weight was $65 \mathrm{~kg}$, erythrocyte sedimentation rate $87 \mathrm{~mm}$ in the first hour, aspartate transaminase activity 145 IU/1 (normal 22), and alkaline phosphatase activity $480 \mathrm{IU} / 1$ (normal 92). 5-Hydroxyindole-acetic acid was not detected in urine. He started treatmen with cyproheptadine $4 \mathrm{mg}$ three times a day in May, and within one week pain in the right hypochondrium had improved considerably. In August ultrasonography showed improvement in the liver appearance. The erythrocyte sedimentation rate had fallen to $10 \mathrm{~mm}$ in the first hour, aspartate transaminase activity to $22 \mathrm{IU} / 1$, and alkaline phosphatase activity to $264 \mathrm{IU} / 1$. The liver edge was $8 \mathrm{~cm}$ below the right costal margin, and he had gained $5 \mathrm{~kg}$ in weight.

\section{Comment}

In the past year we have seen 12 patients with carcinoid tumours or apudomas, of whom six had symptoms of the carcinoid syndrome that were sufficiently severe for us to try cyproheptadine. Thus two out of seven patients (including case 2) treated with cyproheptadine have shown an objective response.

Spontaneous regression of carcinoid tumours has not been described, but necrosis has been found in the centres of hepatic secondaries examined post mortem. ${ }^{2}$ Carcinoid tumours may produce serotonin, histamine, and kallikrein. Bradykinin and histamine are hepatic arterial vasodilators, and serotonin is a vasoconstrictor. ${ }^{3}$ Since cyproheptadine blocks serotonin 1 , serotonin 2, and histamine $\mathrm{H}_{1}$ receptors, it may have modulated blood supply to the secondary deposits. There were no clinical effects similar to those found after embolisation, ${ }^{4}$ however, and this would not explain the improvement in case 2 .

Some xenografts of human colon cancer have regressed after treatment with an antiserotonin compound or cimetidine. ${ }^{5}$ Thus cyproheptadine may possibly have affected tumour growth by blocking the effects of amine hormones.

We thank Mr T A Waterworth, Hospital of St Cross, Rugby, for referring case 1 , and Dr E Wiltshaw, Royal Marsden Hospital, for referring case 2.

${ }^{1}$ Hill GJ. Carcinoid tumours, pharmacological therapy. Oncology 1971 ;25: 329-43.

2 Bonomi P, Hovey C, Dainauskas JR, Slayton R, Walter J. Management of carcinoid syndrome. Med Pediatr Oncol 1979;6:77-83.

3 Richardson PDI, Withington PG. A comparison of the effects of bradykinin, 5-hydroxytryptamine and histamine on the hepatic arterial and portal venous vascular beds of the dog: histamine $\mathrm{H}_{1}$ and $\mathrm{H}_{2}$ receptor populations. Br $\mathcal{F}$ Pharmacol 1977;60:123-33.

4 Allison DJ, Modlin IM, Jenkins WJ. Treatment of carcinoid liver metastases by hepatic artery embolisation. Lancet 1977 ;ii:1323-5.

5 Tutton PJM, Steel GG. Influence of biogenic amines on the growth of xenografted human colorectal carcinomas. Br $\mathcal{F}$ Cancer $1979 ; 40: 743-9$.

(Accepted 14 May 1982)

Royal Marsden Hospital, London SW3 6JJ

ADRIAN L HARRIS, DPHIL, MRCP, lecturer in medicine (present address :

Imperial Cancer Research Fund, Mill Hill Laboratories, London NW7 $1 \mathrm{AD})$

IAN E SMITH, MD, MRCP, consultant medical oncologist

\section{Clostridium difficile in toxic megacolon complicating acute inflammatory bowel disease}

Acute colonic dilatation is an important complication of inflammatory bowel disease, though the precise aetiology remains unknown. We describe two cases in which Clostridium difficile and its toxin were detected and in which metronidazole produced symptomatic resolution and eradicated the toxin and organism.

\section{Case reports}

Case 1-A 39-year-old man with no past history of bowel disturbance or recent exposure to antibiotics presented with a seven-week history of increasingly severe bloody diarrhoea. He was unwell, his temperature was $39 \cdot 4^{\circ} \mathrm{C}$, pulse 120 beats $/ \mathrm{min}$, haemoglobin concentration $10 \cdot 4 \mathrm{~g} / \mathrm{dl}$, white cell count $18 \times 10^{9} / 1$, and albumin concentration $29 \mathrm{~g} / \mathrm{l}$, and his abdomen was distended. Plain abdominal radiography showed the transverse and ascending colon to be severely dilated (maximum diameter $8.5 \mathrm{~cm}$ ). Toxic megacolon secondary to presumed acute inflammatory bowel disease was diagnosed and treatment with intravenous hydrocortisone begun. Stool analysis on admission showed a cytopathic toxin in cell culture, neutralised by $\mathrm{Cl}$ sordellii antitoxin (Wellcome Foundation), and stool culture grew $\mathrm{Cl}$ difficile. Metronidazole $400 \mathrm{mg}$ eight-hourly by mouth was given for seven days, and within 48 hours after the first dose the colonic distension had disappeared. By eight days the diarrhoea had stopped, neither $\mathrm{Cl}$ difficile nor its toxin was detectable in the faeces, and he was clinically well. Subsequen 
investigation showed extensive colonic and ileal Crohn's disease with compatible histological findings and radiological skip lesions.

Case 2-An 82-year-old woman with a four-month history of bloody diarrhoea was shown to have extensive ulcerative colitis on barium enema, confirmed by sigmoidoscopy and biopsy. Oral prednisolone $(40 \mathrm{mg} / \mathrm{day})$ failed to produce improvement, and two weeks later her transverse colon became noticeably distended $(9 \mathrm{~cm}$ transverse diameter on plain abdominal radiograph). She was feverish $\left(38.7^{\circ} \mathrm{C}\right)$, with haemoglobin concentration $10.7 \mathrm{~g} / \mathrm{dl}$, white cell count $16.7 \times 10^{9} / 1$, and albumin concentration $26 \mathrm{~g} / 1$. Intravenous hydrocortisone and blood transfusion produced initial improvement, but 10 days later the diarrhoea worsened and the colon distended again. Faecal samples at and during admission contained a neutralisable cytopathic toxin, and stool culture grew $\mathrm{Cl}$ difficile. Intravenous metronidazole $500 \mathrm{mg}$ eight-hourly was begun, and over the next four days the diarrhoea improved and the colonic dilatation disappeared. After eight days of treatment neither faecal toxin nor $\mathrm{Cl}$ difficile was detectable. Three weeks later, however, the patient died from a massive pulmonary embolism.

\section{Comment}

Acute toxic dilatation of the colon (toxic megacolon) is an uncommon but well-recognised complication of both ulcerative colitis and Crohn's disease. ${ }^{2}$ The condition is usually a feature of severe and extensive disease and may occur as the presenting feature of previously unrecognised inflammatory bowel disease. Mortality is around $30 \%$, and surgery is often required when medical intervention fails or colonic perforation occurs. ${ }^{1}$ Investigations such as sigmoidoscopy and contrast radiography may be possible triggering factors and should be performed with caution in any patient with severe active disease; nevertheless, toxic dilatation occurs in their absence, and to date no specific aetiological factors have been identified. $\mathrm{Cl}$ difficile is now the accepted major aetiological agent of pseudomembranous and antibioticassociated colitis and has been incriminated in relapses of inflammatory bowel disease. ${ }^{34}$ That the organism was detected in our patients suggests that it may also be relevant in toxic dilatation of the colon. Interestingly, the symptoms in our second patient responded only partially to intravenous steroids with persistence of $\mathrm{Cl}$ difficile. Metronidazole produced a rapid and sustained clinical improvement with eradication of toxin and organism in both patients, thus averting potentially hazardous surgery.

We suggest that $C l$ difficile may be implicated in toxic colonic dilatation complicating acute inflammatory bowel disease, unrelated to antibiotic exposure, and that routine faecal screening for $\mathrm{Cl}$ difficile toxin should be performed in all patients with inflammatory bowel disease in relapse.

${ }^{1}$ Binder SC, Patterson JF, Glotzer DT. Toxic megacolon in ulcerative colitis. Gastroenterology 1974;66:909-15.

2 Javatt S, Brooke B. Acute dilatation of the colon in Crohn's disease. Lancet 1970 ;ii:126-7.

${ }^{3}$ Bolton RP, Sherriff RJ, Read AE. Clostridium difficile associated diarrhoea -a role in inflammatory bowel disease? Lancet 1980;i:383-4.

4 Trnka YM, Lamont JT. Association of C difficile toxin with symptomatic relapse of chronic inflammatory bowel disease. Gastroenterology 1981; $80: 693-6$.

(Accepted 12 May 1982)

University Department of Medicine, Bristol Royal Infirmary, Bristol BS2 8HW

ROBIN P BOLTON, MA, MRCP, research fellow and honorary senior registrar (now lecturer in medicine, University Department of Medicine, St James's Hospital, Leeds LS9 7TF)

ALAN E READ, MD, FRCP, professor to be more effective. We carried out a double-blind study to assess the effect of ranitidine.

\section{Patients, methods, and results}

In a double-blind study 158 consecutive patients presenting to this hospital over 12 months with acute upper gastrointestinal haemorrhage were randomised to receive oral ranitidine $150 \mathrm{mg}$ thrice daily, to maximise inhibition of gastric acid, or a matching placebo tablet. Treatment was started in the casualty department. Patients underwent endoscopy within 24 hours and were maintained on the trial treatment for 10 days. No specific antacids were prescribed. The severity of bleeding was classified as mild (blood loss estimated at less than three units, with no clinical shock), moderate (blood loss of three to six units and tachycardia with or without hypotension), or severe (grossly clinically shocked with tachycardia of over 110 beats/min, hypotension with a systolic pressure less than $95 \mathrm{~mm} \mathrm{Hg}$, and estimated blood loss of more than six units). Patients were examined regularly for evidence of rebleeding, which was defined by clinical assessment, taking into account further haematemesis, fresh melaena, sustained tachycardia or hypotension, or an appreciable fall in haemoglobin concentration. Decisions on managing individual cases were made by five doctors attending the patients independently of the trial. A preliminary study showed that absorption of a single $150 \mathrm{mg}$ oral dose of ranitidine was similar in six patients with acute haemorrhage to absorption in normal volunteers and patients with ulcers.

The table shows the incidence of rebleeding in the 151 patients who completed the trial broken down into the individual categories of lesions.

Numbers of patients with each type of lesion, and numbers rebleeding

\begin{tabular}{|c|c|c|c|c|}
\hline & \multicolumn{2}{|c|}{ Ranitidine } & \multicolumn{2}{|c|}{ Placebo } \\
\hline & Total & Rebleeding & Total & Rebleeding \\
\hline $\begin{array}{l}\text { Duodenal ulcer: } \\
\text { Total No of patients } \\
\text { No aged over } 60 \\
\text { Gastric ulcer: }\end{array}$ & $14^{27}$ & $2^{3^{*}}$ & $17^{26}$ & $9^{11^{*}}$ \\
\hline $\begin{array}{l}\text { Total No of patients } \\
\text { No aged over } 60\end{array}$ & ${ }_{11}^{13}$ & $4^{4}$ & $9^{15}$ & $2^{5}$ \\
\hline Gastritis & 6 & 2 & 5 & 1 \\
\hline $\begin{array}{l}\text { Duodenitis } \\
\text { Oesophagitis }\end{array}$ & 7 & $\begin{array}{l}0 \\
0\end{array}$ & 3 & 0 \\
\hline $\begin{array}{l}\text { Oesophagitis } \\
\text { Varices }\end{array}$ & $\begin{array}{l}7 \\
6\end{array}$ & $\begin{array}{l}0 \\
3\end{array}$ & 11 & $\begin{array}{l}0 \\
3\end{array}$ \\
\hline Mallory-Weiss & 4 & 0 & 5 & 0 \\
\hline Carcinoma & $i$ & 0 & 2 & 0 \\
\hline $\begin{array}{l}\text { No diagnosis } \\
\text { Vascular }\end{array}$ & $\begin{array}{l}3 \\
2\end{array}$ & $\begin{array}{l}0 \\
2\end{array}$ & 3 & 1 \\
\hline & & & & \\
\hline Total & 76 & 14 & 75 & 21 \\
\hline
\end{tabular}

$* \mathrm{p}<0.05$.

Significant benefit was noted among those with duodenal ulcer who received ranitidine as compared with placebo $(p<0 \cdot 05)$. Most peptic ulcers that rebled were in patients aged over 60 . Seven patients were withdrawn from the trial: six because they were judged not to be bleeding from the upper gastrointestinal tract and one because of a rash that had probably been present before randomisation. The tendency to rebleed increased with the severity of initial bleeding, but there were similar numbers in the two treatment groups of patients with mild initial bleeds (two rebleeds in 13 patients receiving ranitidine; three in 12 receiving placebo); moderate initial bleeds (five rebleeds in 38 receiving ranitidine; seven in 41 receiving placebo); and severe initial bleeds (seven rebleeds in 25 receiving ranitidine; 11 in 22 receiving placebo). The groups were similar with respect to age, number aged over 60 , sex, haemoglobin concentration on admission, and rise in serum urea concentration. The proportions of patients undergoing surgery were similar in the two groups (11 of 76 receiving ranitidine $(14.5 \%) v 15$ of 75 receiving placebo $(20 \%))$. Five patients receiving ranitidine $(6 \cdot 6 \%)$ and four receiving placebo $(5 \cdot 3 \%)$ died.

\section{Comment}

This study is the first to have used ranitidine in acute upper gastrointestinal haemorrhage. Although no overall benefit was noted, the incidence of rebleeding in patients with duodenal ulceration was significantly reduced. Since this was not found previously with cimetidine, ${ }^{4}$ we might speculate that the increased potency of ranitidine $^{5}$ may be responsible for the difference. This study also emphasises the adverse effects of age and severity of initial bleed on the predisposition to rebleed. Our results with oral ranitidine, which is convenient and safe, are encouraging and indicate that the drug should be evaluated further in this common serious medical condition.

We thank Mrs G Croxton for her invaluable help in co-ordinating this study, Miss Dawn Cox for typing the manuscript, the physicians of Selly Oak Hospital for their permission to study patients under their care, and

\section{Ranitidine in acute upper}

Mortality from acute upper gastrointestinal haemorrhage has remained unchanged for 25 years, despite improvements in diagnostic and surgical techniques. ${ }^{1}$ Rebleeding aft the major factors contributing to mortality. ${ }^{2}$ Despite its early promise
in bleeding patients with hepatic failure ${ }^{3}$ cimetidine failed to reduce the incidence of rebleeding when given to all patients presenting with acute upper gastrointestinal haemorrhage. ${ }^{4}$ Ranitidine, however, a more potent inhibitor of secretion of gastric acid, ${ }^{5}$ might be expected 